University of California, Hastings College of the Law UC Hastings Scholarship Repository

Faculty Scholarship

$1-1-1997$

\title{
Environmental Management Systems and Environmental Protection: Can ISO 14001 Be Useful Within the Context of APEC?
}

Naomi Roht-Arriaza

UC Hastings College of the Law, rohtarri@uchastings.edu

Follow this and additional works at: https://repository.uchastings.edu/faculty_scholarship

\section{Recommended Citation}

Naomi Roht-Arriaza, Environmental Management Systems and Environmental Protection: Can ISO 14001 Be Useful Within the Context of APEC?, 6 J. Env't \& Dev. 292 (1997).

Available at: https://repository.uchastings.edu/faculty_scholarship/1302

This Article is brought to you for free and open access by UC Hastings Scholarship Repository. It has been accepted for inclusion in Faculty Scholarship by an authorized administrator of UC Hastings Scholarship Repository. For more information, please contact wangangela@uchastings.edu. 


\title{
Environmental Management Systems and Environmental Protection: Can ISO 14001 Be Useful Within the Context of APEC?
}

\author{
NAOMI ROHT-ARRIAZA
}

\begin{abstract}
At the July 1996 Ministerial Meeting on Sustainable Development, the environment ministers of the Asia Pacific Economic Corporation's (APEC's) 18 members agreed to promote ISO 14000, which involves voluntary action by industry to establish environmental management systems (EMSs) and to commit to ongoing improvements in environmental performance. This article analyzes the potential role of the ISO 14001 EMS and related standards in the context of the economies of APEC. It summarizes the genesis and content of the standards and then focuses on aspects that are particularly salient within the APEC context: performance, information generation, and market access. It concludes that ISO 14001 alone will not necessarily lead to improvement in environmental outcomes in the region. The final section explores some options for incorporating ISO 14001 as one element of a larger framework for environmental protection, international cooperation, and sustainable development in APEC.
\end{abstract}

\section{APEC and the Environment}

The Asia Pacific Economic Corporation's (APEC's) 18 members span East Asia, Australasia, and the Western Hemisphere and include states with different kinds and levels of industrial development. These include two big-market countries-the United States and Japan-as well as the world's fastest growing economies and some of the most polluted places on earth (Zarsky, 1996). Since the early 1990s, these economies have put in place a process to gradually liberalize trade and investment barriers, to facilitate trade and investment, and to increase economic and technical cooperation.

APEC functions through a series of regular meetings among government officials at different levels. Outside of summits of heads of state, major decisions are taken by the senior officials meeting (SOM), which brings together economic, trade, and finance ministers of the participating economies. In addition, a wide variety of working groups, task forces, experts' groups, and the like confer on narrower policy issues.

AUTHOR'S NOTE: Some of the material was published in an earlier version in the Fall 1997 Georgetown International Environmental Law Review.

Journal of Environment \& Development, Vol. 6, No. 3, September 1997 292-316 (c) 1997 Sage Publications, Inc.

292 
The focus is on trade integration and removal of barriers to trade but also, and increasingly, on sharing of information, technical expertise, and policy coordination in a wide range of areas. There is no intention to create joint regulatory structures or deeper integration (Zarsky, 1996).

As part of this series of meetings, APEC's environmental ministers first met in March 1994, producing a set of Principles for Sustainable Development (Zarsky, 1996, p. 10). Rather than create an environmental committee, which risked marginalization from the central trade and investment agenda, in February 1995 the SOM agreed that all APEC committees and working groups should include environmental issues as part of their reporting requirements. Thus, at least potentially, APEC is more fluid, less institutionalized, and more open to cross-cutting initiatives that integrate trade and environment concerns from the beginning.

The July 1996 Ministerial Meeting on Sustainable Development reiterated the cross-cutting nature of environmental issues and developed a three-part action program (APEC, 1996). One of the three major components of the program deals with clean production/clean technology (APEC, 1996). It will, among other things, formulate specific strategies for industrial and agricultural sectors, mobilize public-private partnerships in major industry sectors to promote cleaner production, include capacity building, training, information sharing, access to expert input, and the like. As part of the cleaner production strategy, the environment ministers pledged to promote "ISO 14000, which involves voluntary action by industry to establish environmental management systems and commit to continuous improvements in environmental performance" (APEC, 1996, p. 3).

For APEC, a focus on ISO 14000 makes sense from a number of angles. Because the system is voluntary and does not set any uniform substantive requirements, it fits well into a regional vision of national policy coordination rather than regional level harmonization. Interest from environmental ministers also responds to their need to fit environmental policy into a trade liberalization framework. ISO 14000 has the potential both to facilitate "greener" trade and, paradoxically, to become a trade barrier itself at the very moment when global and regional trade agreements were to have opened markets.

This article evaluates both the potential and the limitations of ISO 14001 as a vehicle for environmental improvement. It focuses on a number of areas in which the standard falls short and then looks at how an organization such as APEC might be most useful in both using the strengths of an environmental management approach and filling in some of the weaknesses. It concludes that APEC promotion of ISO 14000, in isolation, is likely to do little to improve environmental performance and may even be counterproductive. However, if APEC broadens its approach to view environmental management systesm (EMSs) as only one element of a wider array of policy tools, it could play a positive role. 


\section{What is ISO 14000?}

ISO 14000 was created and approved last year by the International Organization for Standardization, a federation of more than 100 national standardization bodies, one from each represented country. Whereas delegations can (and often do) include government officials, the drafting committee for the 14000 series was dominated by industry and consultants, those most concerned with the financial and other implications of the proposed standards (Roht-Arriaza, 1995; United Nations Conference on Trade and Development [UNCTAD], 1996).

The ISO 14000 series extends the management systems approach first pioneered in ISO's 9000 series to environmental management. ISO 14001, the environmental management standard, is the centerpiece of the 14000 series. To conform, company management must first define the organization's environmental policy and ensure that it is appropriate to the nature, scale, and environmental impacts of the organization's activities. Each organization must commit to continual improvement, to compliance with relevant laws and other requirements, and to prevention of pollution. The environmental policy must be publicly available and must contain a documented framework for setting and reviewing environmental objectives and targets; assessments of environmental impacts need not be published (ISO 14001, $§ 4.2,4.3$ ).

Once plans, objectives, and timetables are in place, management must designate responsibility for achieving targets, provide necessary resources (ISO 14001, $\S 4.41$ ), train appropriate personnel ( $\$ 4.4 .2$ ), and prepare an emergency response plan $(\$ 4.4 .7)$ These activities must be periodically monitored and corrective action taken in cases of noncompliance (\$ 4.5). Periodic environmental audits, whether internal or external, are required $(\$ 4.7)$. Such audits may be used by certification bodies to help verify conformance with the EMS. In addition, periodic management reviews are to evaluate the system's continuing effectiveness $(\S 4.6)$. The existence of an adequate system may be self-certified or a firm may seek third-party verification to certify that it conforms to the standard (ISO 14001, Introduction, pp. v-vi).

\section{Advantages and Limitations of the ISO 14001 EMS Standard}

An EMS-based approach relies heavily on the idea that changes in corporate organization, culture, and procedures can yield environmental improvement in ways that a compliance-based approach cannot. As a global standard, it also relies on the idea that certification to the standard can provide uniform assurances of environmental probity to buyers and 
consumers and thus can facilitate trade while driving improvement through market incentives. In evaluating the usefulness of the EMS embodied in ISO 14001, three questions are important: whether implementation of the system will lead to improved environmental performance, whether an EMS can improve the production and availability of information, and whether a market-based, market-enforced approach enhances or limits access to markets. I explore these aspects in turn.

\section{PERFORMANCE AND PUBLIC INFORMATION CONCERNS}

The EMS standard requires no set level of environmental performance to obtain certification. It "does not establish absolute requirements for environmental performance beyond commitment, in the policy, to compliance with applicable legislation and regulation and to continual improvement" (ISO 14001, Introduction). An annex elaborates the following:

The rate and extent of [continual improvement] will be determined by the organization in the light of economic and other circumstances. . . The establishment and operation of an EMS will not, in itself, necessarily result in an immediate reduction of adverse environmental impact. (ISO 14001, Annex A, A.4.0)

This purely procedural approach has some advantages. It allows organizations of all sizes and from all areas to set their own goals. Unlike traditional technology-based standards, it does not require imposition of the same technology on firms with different needs and costs, avoiding some of the economic inefficiencies of command-and-control rules. It avoids the potential trade barrier problems posed by attempts to harmonize performance standards across borders and allows maximum flexibility for management.

Moreover, if implemented in good faith, it may diffuse environmental values throughout a corporate culture, starting with its top management. The standard's drafters hope a systems approach will incorporate environmental concerns into every business decision (Cascio, 1994; International Institute for Sustainable Development [IISD], 1997). Moreover, rather than limit the focus to legal compliance with a limited set of parameters, it can widen the range of possible environmental measures and encourage continual improvement.

A systems approach, however, means no bottom line or minimal performance standard is necessary to conform to the standard. Thus, there is no prescribed floor or minimum standard beyond a commitment to comply with local law. Companies that set extremely lenient goals for themselves, and meet them, will conform to the standard to the same or 
greater extent than those companies that set themselves more ambitious, and more difficult to realize, objectives.

The basic requirement of ISO 14001 is a public environmental policy. The policy goals and specific timetables and measurements for improvement established in the policy become auditable. The policy must contain a commitment to continual improvement and to setting and reviewing environmental objectives and targets. It must also contain a commitment to pollution prevention and to "comply with relevant environmental legislation and regulations and with other requirements to which the organization subscribes" ( $\$ 4.3 .2)$.

The commitment to comply with local law at first glance seems almost redundant because companies presumably are already under a legal obligation to comply. However, given weak or nonexistent enforcement of environmental laws in much of the world, especially in developing countries, an alternative method of coaxing or inducing companies to come up to compliance would be welcome. The third parties certifying conformance with ISO 14001 could become, indirectly, additional resources to monitor legal and regulatory compliance and allow regulators to focus on the worst violators. Unfortunately, the availability of self-certification and the weaknesses in the certification system, discussed below, limit the potential scope of this benefit.

The commitment to compliance goes beyond local law to encompass codes of conduct and other "requirements to which the organization subscribes." These might include industry codes, internal company standards, and agreements with public authorities or those arising from partnerships with government or nonprofit groups. This provision could provide a way to verify the commitments an organization has taken on through signing the Business Charter for Sustainable Development (BCSD) or other similar initiatives, most of which rely only on self-reporting to monitor conformance with their provisions (Bell, 1997, p. 72). It could also provide a way of checking on adherence to internal standards set by many global corporations. Because these other commitments do sometimes include more substantive requirements in the areas of emissions and waste reduction, public access to data, and the like, it should be possible to use ISO 14001 to verify these more far-reaching commitments for those companies that choose to assume them. Thus, one way to strengthen the ISO 14001 standard would be to encourage its use in combination with adherence to other green industry codes and similar programs.

The requirement of continual improvement is potentially one of the most far-reaching, moving organizations beyond a compliance-focused "bright line." However, its formulation in ISO 14001 is extremely problematic. Continual improvement is defined as the 
process of enhancing the environmental management system [italics added] to achieve improvements in overall environmental performance, in line with the organization's environmental policy. Note: The process need not take place in all areas of activity simultaneously. (ISO 14001, § 3.1)

Thus, whereas the ultimate goal may be real improvement, all that is arguably required is better systems over time. In a related issue, the audit required under ISO 14001 is a management systems audit designed to evaluate if the proper procedures have been put in place and maintained; it is not a compliance or performance audit, although it will check whether information to track performance has been recorded. Indeed, the definition of an EMS audit specifies that audit criteria may be set by the organization itself $(\S 3.7)$. Recent debates have made clear that even noncompliance with applicable law will not defeat certification to the standard, so long as the noncompliance was registered by the management system and proper procedures are followed to abate the problem (Bell, 1997, p. 78).

Moreover, an attempt by several delegations to tie continual improvement to the goal of reducing impacts to levels not exceeding those corresponding to economically viable application of best available technology was rebuffed. The standard reads: "The EMS should encourage organizations to consider [italics added] implementation of best available technology where appropriate and where economically viable" (ISO 14001, Introduction). This contrasts to the European Management and Audit Scheme (EMAS), ${ }^{1}$ which requires continual improvement of a participating site's actual performance in 11 specified areas set out in an annex. It is also tied to a given performance level: EMAS (1993) Article 3(a) requires "reasonably continuous improvement of environmental performance, with a view to reducing environmental impacts to levels not exceeding those corresponding to economically viable application of best available technology." The audit must evaluate performance as well as management systems (EMAS, 1993, art. 4).

An organization must also commit to prevention of pollution. This language, inserted by the U.S. delegation, could have been positive, going beyond compliance with existing laws in line with much current thinking on environmental protection. However, the definition is so watered down as to be almost meaningless. It includes processes to

1. European Commission (EC) Council Regulation 1836/93. The regulation became effective as of April 1995. It allows firms with European sites to voluntarily establish environmental management and auditing systems that are then registered through national bodies. European Management and Audit Scheme (EMAS) requirements are stricter than those of ISO 14001 in a number of respects, including a closer tie to performance, specified parameters to be considered in an environmental register, publication of a summary of audit results, and mandatory third-party certification prior to registration. 
control pollution, which may include recycling, treatment, and others (ISO 14001, § 3.14). According to the U.S. Environmental Protection Agency (EPA) and many other experts, neither simple pollution control nor after-the-fact treatment or off-site recycling are really prevention, which focuses on changes in process, practices, and materials to avoid introducing pollutants into the environment at all. ${ }^{2}$

The information collection and publication provisions of ISO 14001 are similarly disappointing. An organization must put in place a "procedure to identify the environmental aspects of its activities, products and services that it can control and over which it can be expected to have an influence, in order to determine those which have or can have significant impacts on the environment" (\$ 4.4.3). However, the procedure is weak because the kind of data, and the kind of environmental impacts that must be inventoried, are left completely to the discretion of each organization, and the organization need only consider these impacts in setting objectives and targets. ${ }^{3}$

More important, ISO 14001 does not require publication of an environmental register or publication of audit results. Only the environmental policy need be public. Elsewhere, the standard merely requires that an organization considers the views of interested parties in formulating objectives and considers "processes for external communication on its significant environmental aspects and record its decision" (\$4.3.3). EMAS, by contrast, requires evaluation of a specified group of parameters, including resource use; waste disposal; impacts to air, water, land, and natural resources; accidents; and the potential effects of new products and new or changed processes, as well as the production of an environmental register on the basis of this evaluation (EMAS, 1993, Annex 5). It requires a public environmental statement, which must include a summary of figures on pollutant emissions, waste generation, use of raw materials, energy, and water; an assessment of significant issues; a description of policy, program, and systems at the site; and the name of the accredited verifier (EMAS, 1993, AA.3[f], 5). The public statement is seen as essential to ensure improved environmental performance.

Attempts to include mandatory publication of information in ISO 14001 foundered on U.S.-led fears that such data could be used in litigation or by regulators and would create pressure for cosmetic, rather than real, audits (Bell \& Connaughton, 1993). Although such concerns may be valid, they might have been dealt with through case-specific

2. The EPA's pollution prevention strategy distinguishes on-site or closed loop recycling, which is a recognized prevention strategy, from off-site recycling, which generally is not (U.S. EPA, 1992). ISO 14001 makes no such distinction.

3. Whereas an annex does specify that such a procedure generally involves inventories of air emissions, releases to water and land, waste management, and the like (ISO 14001, A.4.2.1.2), none of these is mandatory; each organization can decide to use them or not, as appropriate. Nor are there at present standardized methods for measuring these parameters. 
confidentiality or audit protection rules while still requiring enough disclosure to safeguard the integrity of a market-driven process.

In short, it is possible to use ISO 14001 to create a performance-oriented, best practice-based system that makes adequate disclosure of a company's impacts and performance-it is just not required. Thus, to strengthen the standard's usefulness, those interested in performance and disclosure should differentiate among ISO 14001-compliant firms based on the quality and content of their stated policies, especially the specificity and stringency of their goals and their willingness to disclose adequate information. But the price of such differentiation will be losing the uniformity of requirements that made a global standard attractive in the first place.

\section{ISO 14001 Acceptance in APEC Economies: Love for All the Wrong Reasons}

Even before the ISO 14001 standard was finalized and published, companies were announcing their certification to the standards, and hordes of consultants were offering training courses, manuals, and advice on how to become certified. Nonetheless, the available evidence to date shows that many large companies either have in place or are putting in place EMSs but are not necessarily applying for formal certification to the standard. This wait-and-see attitude is most pronounced in the United States. Asian industry has been most enthusiastic about both implementation and certification: In most Asian countries, government agencies are gearing up to accredit certifiers, disseminate information, train industry, and the like. Still, no government to date has said it will make conformance mandatory, and most have been quite cautious about changing their regulatory structures to lean more heavily on voluntary systems, such as ISO 14001 .

A brief review of actions taken in selected APEC economies illustrates the scope of existing actions.

United States. Whereas many U.S. companies, especially those that sell in global markets, either have in place or are preparing their own plans for an EMS, to date there has been no rush toward certification. The EPA is discussing with other federal agencies the potential use of ISO 14001 in conjunction with procurement policies. Participants in EPA's Environmental Leadership Program must have an EMS in place for 2 yearswhereas ISO 14001 provides a suitable EMS, certification to the standard is not mandatory. ${ }^{4}$ The Department of Justice has indicated some skepticism about the role of ISO 14001 certification in criminal and civil

4. The Environmental Leadership Program provides that facilities meeting its criteria receive expedited permitting, reduced inspections, a 60-day window in which to correct 
enforcement actions. A number of states, including Pennsylvania and California, are looking at ways of combining an EMS with other requirements in streamlined permitting and enforcement procedures.

Canada. Although regulators have generally not embraced the standard, one provincial court has imposed an ISO 14001 certification as part of enforcement proceedings. The Alberta court required Prospec Cdn, a mining reagent manufacturer, to become certified to the standard by mid-1998, in addition to fining the company for exceeding air pollution standards ("Canadian Court," 1996).

China. In October 1996, China established a federal committee to introduce the ISO 14000 series in China as Chinese National Standards. The committee includes the National Environmental Protection Agency and the State Technological Supervision Bureau. The bureau is considering an EMS pilot project to test whether the standard could be used to ease government regulations ("Chinese Government," 1996). Observers have pointed to the difficulties in implementing ISO 14000 at the level of both state-owned and township and village enterprises, given their high debt levels and old technology (IISD, 1997). Accordingly, most standard-related activity has focused on the export sector; for example, China designated the port of Xiamen, one of five special economic zones and one where foreign-owned enterprises account for $70 \%$ of industrial output, as the first pilot city for ISO 14001 implementation ("China," 1997). In addition, China is developing criteria for registrars, course providers, and auditor certification; two government agencies will administer an accreditation program.

Japan. More than 120 Japanese companies, mostly large export-oriented manufacturers, have become certified either to ISO 14001 or to its predecessor, BS 7750. The electronics, steel, and automotive sectors have been particularly interested. ISO 14001 has been adopted as a Japan Industrial Standard, and an accreditation body (Japanese Accreditation Board) for certifiers had as of 1996 seven certification bodies and four training bodies under its pilot program (Kurasaka, 1996). The electronics industry has its own certification body, and a number of other local certifiers also exist. The Japanese government has supported certification for large companies, and the Ministry of International Trade and Industry has been preparing environmental management plans that conform to ISO 14001 requirements (Kurasaka, 1996) as well as aiding industry in developing sector-by-sector protocols for certification ("Ja-

noncompliance without penalty, and public recognition. In exchange, in addition to an EMS, they must participate in community outreach/employee involvement programs and carry out compliance audits (U.S. EPA, 1996). 
pan Agrees," 1994). There are continuing reports that certification will eventually be required, at least for government contractors ("Japan Agrees," 1994).

Chinese Taipei. Interest in adopting ISO 14000 has been high, in part because of the export-driven nature of much local industry. A high-level government working group has been formed to oversee a Scheme for Promoting Environmental Management Standards (Mapes, 1996b). The Bureau of Commodity Inspection and Quarantine, which has issued ISO 9000 certifications at no cost to Taiwanese industry, will be in charge of accreditation and certification systems. The Industrial Development Bureau (United States-Asia Environmental Partnership [US-AEP], 1996d) will assist industry directly, whereas the EPA will deal with eco-labeling and the Bureau of Foreign Trade will track ISO 14000 requirements. The government-funded Industrial Technology and Research Institute is conducting a pilot EMS program with five diverse plants, and the results will be used to assist other companies.

Australia. Government attitudes toward ISO 14001 have been mixed. The Victoria state government requires an EMS, but not necessarily certification to ISO 14001, as part of an integrated license scheme $e^{5}$ (Hulbert, 1996). On the other hand, the government recently removed references to ISO 14001 certification from its procurement requirements, indicating that the requirement hurt small and medium enterprises (SMEs) ("Canberra Takes Action," 1996).

Singapore. Ninety percent of Singaporean manufacturers provide components for multinational corporations (U.S.-AEP, 1996c). The government's Productivity Standards Board has been certifying companies since July 1996, making Singapore one of the first countries to introduce the scheme. Some 1,200 local industries have signed the Singapore Business Charter for Sustainable Development (U.S.-AEP, 1996c). In September 1996, the government established a coordinating committee to help local companies prepare for ISO 14000; it also has special assistance for SMEs ("Singapore Launching," 1996).

Malaysia. The Standards and Industrial Research Institute has announced adoption of the draft standards and is offering training programs to industry. It plans to offer certification to both Malaysian and Indonesian industry (Mapes, 1996a). It is also conducting pilot schemes

5. The Victoria accredited license scheme involves, in addition to an EMS, a good track record of performance, an environmental improvement plan, an environmental audit system that at some point involves a government auditor, and industry-community liaison groups. Industries receive in exchange the ability to operate within broad environmental parameters, with lessened permit, reporting, and inspection requirements. 
for certification and auditing. The Ministry of International Trade and Industry is encouraging industry to adopt ISO 14000 (U.S.-AEP, 1996b).

Thailand. The Thai Industrial Standards Institute is in charge of promoting the standard, and its National Accreditation Council is the government body authorized to certify firms. The institute has also run training and pilot programs. Thailand's Eighth National Economic and Social Development Five-Year plan reportedly will include a commitment to ISO 14000 implementation (U.S.-AEP, 1996e).

Indonesia. The Standardization Council of Indonesia has formed six working groups (consisting of the environmental enforcement and industry ministries and NGO, university, and industry representatives) to design a certification program for Indonesia ("Indonesia Adopts ISO 14001," 1996). However, most industry directorates within government, and most industry, have only begun thinking about ISO 14000 (U.S.-AEP, 1996a).

Korea. The government has been tracking ISO 14000 activities since 1994 and has said it will require leading Korean companies to achieve certification by the end of 1997 (Davy, 1996). By the end of 1995, 19 Korean companies were registered to the draft standard or to BS 7750 (Davy, 1996). Industry has also been participating in pilot projects and trainings. In addition, South Korea's Ministry of Environment is implementing a program for environmentally friendly companies that requires an EMS, an environmental assessment and improvement plan, and a demonstration of actual improvement; the ministry inspects prior to designating the site as friendly and exempting it from surprise compliance inspections (UNCTAD, 1996, pp. 72-73).

In sum, interest is high among large companies in having an EMS in place, although certification seems to be less of a priority in the United States and more important in Asia. Governments in Asia especially are promoting adoption of the standard, setting up oversight bodies, encouraging training, and so forth. Why? The next section explores the drivers for EMS implementation and some of the problems specifically associated with certification and accreditation.

\section{IMPLEMENTATION IN ASIA:} MARKET ACCESS AS DRIVER

Three possible drivers could lead to widespread industry adoption of ISO 14001: the promise of internal cost savings, efficiencies, and image; the availability of regulatory relief; and marketplace pressures. First, implementation of an EMS may allow firms to improve their compliance 
with existing national laws; reduce exposure to enforcement actions, lawsuits, or community distrust; cultivate a green image; or improve efficiency through waste minimization or input substitutions identified through the EMS process. Second, users may hope for fewer inspections, quicker permitting, or waiver of certain requirements if they show implementation of an EMS, or, as in Canada, an EMS may be imposed as part of remediation for environmental violations or as part of a clean-up plan. Third, companies may implement an EMS or certify to ISO 14001 (or both) because they believe it will bring them commercial advantages. These advantages may be either proactive-as a badge of marketplace distinction or preference-or reactive-as a means of avoiding loss of business.

Of course, one of the potential advantages of ISO 14001 over traditional regulation is precisely that it harnesses business self-interest to environmental improvement without the mediation of state enforcement. As large global businesses begin preferring certified entities, or requiring proof of certification to ISO 14001 or another EMS standard of their suppliers, demand for certification will grow. Especially as global business transforms itself into dense networks of large and small suppliers and contractors, the leverage exercised by large transnational businesses over other firms in their supply chains is potentially quite powerful (Gunningham, 1995). Government procurement policies incorporating a preference or requirement could have similar effects. In some markets, pressure from banks and insurance companies anxious to minimize their own potential environmental liabilities, or from investors looking for a quick investment "green screen" or looking to comply with regulatory disclosure rules, may also create pressure for certification. ${ }^{6}$

Such pressure emanating down the supply chain would encompass a wide range and size of producers, potentially multiplying manyfold the initial impulse toward certification. However, it is as yet unclear whether, and under what circumstances, large global industries will see a business advantage in either complying with ISO 14001 themselves or in encouraging conformance in their suppliers. Unlike ISO 9000, no immediate impact on product quality or useability is associated with better environmental management. Certification requirements may be limited to high-profile companies or sectors, in which a major accident or discharge would reflect badly on the entire industry, or to sectors heavily dependent on exports. On the other hand, fear of being tarred (legally or in reputational damage) by an irresponsible supplier may create pressure

6. In the case of banks and insurers, their leverage depends highly on market conditions. For example, in a market with too many banks and too few borrowers, conditions such as ISO 14001 certification are unlikely. On the other hand, Malaysia and Japan, among others, are considering the imposition of rules regarding disclosure of potential environmental liabilities such as those now required by the U.S. Securities and Exchange Commission (D. Nelson, personal communication, September 30, 1996). 
for large companies to require assurances from their suppliers. In addition, suppliers whose environmental performances leave them vulnerable to government shutdowns or fines may disrupt supply or slow the time to market, both major concerns for large business. Large developed country-based global enterprises may thus serve as transmission belts not only for ISO 14001 certification but for real performance improvement among their suppliers. If so, such enterprises may also be instrumental in providing the training and capacity building to enable suppliers to meet their requirements, through product stewardship ${ }^{7}$ or similar programs.

ISO 14001 itself contains only weak provisions regarding suppliers' adherence to EMSs. Rather than an explicit requirement for evaluation of suppliers, such as that contained in both EMAS (1993, Annex 1, 4[b]) and ISO 9000, ISO 14001 requires only the establishment of "procedures related to the identifiable significant environmental aspects of goods and services used by the organization and communicating relevant procedures to suppliers and contractors" ( $\$ 4.3 .6[\mathrm{c}])$. Nonetheless, many analysts (and consultants) are analogizing the introduction of ISO 14001 to that of ISO 9000 , the quality standard. In the ISO 9000 case, businesses and government agencies, especially in Europe, began requiring certification as a condition of contracting. ${ }^{8}$ As most certifiers were based in Europe, non-European industry suffered a significant disadvantage as costs were higher and it took longer for them to seek certifications. That experience has left a bitter taste especially in the mouths of Japanese and other Asian industry. Moreover, there are already some reports of companies losing business because of a lack of ISO 14001 certification. ${ }^{9}$

If governments and private customers in one or more major export market begin preferring ISO-certified suppliers, many producers, especially in developing countries, worry that they will be left out or, at the least, will find certification more difficult than will European and North American industries. This has led, on one hand, to a good deal of resentment against what many exporters see as yet another nontariff barrier aimed at developing country economies and, on the other, to widespread interest in making sure local industry is out in front of the curve in a way it was not when ISO 9000 was introduced.

7. Product stewardship involves companies' taking responsibility for the use and disposal of their products as they move down a chain to intermediate customers to ultimate consumers. Thus, for instance, a chemical feedstock manufacturer would take responsibility for ensuring the safe use and disposal of chemicals used by his or her downstream customers (see, e.g., Gunningham, 1995).

8. ISO certification was required for certain "regulated products" covered by EC directives, as well as for some government contracts (Johnson, 1993, p. 9).

9. $B \& Q$, a large British home improvement corporation, reportedly dropped one of its tropical timber suppliers because of failure to conform to ISO 14001 ("Japan: Environment," 1996). 
The nontariff barrier issue should not be legally significant so long as restrictions are imposed simply through market mechanisms, without government preferences or requirements. ${ }^{10}$ Moreover, because it is an international standard, ISO 14001 is presumptively valid under international trade law. ${ }^{11}$ Nonetheless, large, developed country industry will find it easier to put a certifiable EMS in place because many companies already have EMSs and because they have greater physical infrastructure as well as technical and financial capability (United Nations Industrial Development Organization [UNIDO], 1996). Those companies that are already certified to ISO 9000 may also find it easier to create an ISO 14001-based EMS. In the Southeast Asian region, for example, there are few technical assistance programs or university courses in pollution prevention, and consultants in the region focus on pollution control and environmental impact assessment, not on "continual improvement" (Hamner, 1996). But this is not necessarily a reflection of a trade barrier. It may simply be that a more stringent regulatory structure has allowed developed country industry to get a head start. In that sense, the developed country advantage is simply an aspect of comparative advantage.

A more serious worry is that a preference or requirement for ISO 14001-certified firms may exacerbate the disadvantages of SMEs, many of which are based in developing countries. An attempt to tailor a standard to SMEs failed during drafting, although some specific guidance documents are now available. Nonetheless, the proportional costs for SMEs will be greater than for large firms, especially if outside certification is required: SMEs are less likely to have an existing quality system or EMS; are less likely to have in-house personnel available to design the system and to require (expensive) outside consultants; are more likely to have older, more polluting equipment; and are likely to face higher training costs, with less ability to pay for them. At its worst, such disproportionality could become a barrier to new entrants into some sectors.

10. See IISD (1997, p. 25); it might be possible, although unlikely, to argue for application of the General Agreement on Tariffs and Trade/World Trade Organization (GATT/WTO) rules because of government participation in the drafting of the standards. Once an ISO 14001 requirement is built into regulation or procurement, challenges might be possible based, for example, on differential access and costs of third-party certification. A full discussion is beyond the scope of this article; see Roht-Arriaza (1995).

11. The GATT 1994 Agreement on Technical Barriers to Trade (TBT) states that "where technical regulations are required and relevant international standards exist or their completion is imminent, Members shall use them, or the relevant parts of them, as a basis for their technical regulations" (GATT, 1994, p. 1428). It thus creates a preference for international standards and a presumption that international rules are consistent with GATT. Use of the standard, especially in procurement by governments, still raises interesting legal questions. It is unclear whether an EMS standard with no substantive requirements constitutes a "process and production method" and whether, as such, it is encompassed by the TBT. It is also unclear to what extent private use of the standard is subject to WTO disciplines at all. These subjects are beyond the scope of this article. 
A supply chain-based motivation for EMS implementation and certification entails dangers. The depth and strength of a company's commitment to environmental improvement through implementation of an EMS will vary depending on the reason for implementing the scheme. Those companies that adopt the standard for internally generated reasons are most likely to take it seriously and to stress real performance improvements, whereas those conscripts who act in response to market pressures or are forced into too-quick adoption may see it more as yet another paper-shuffling enterprise focused merely on obtaining the correct label. This will especially be true when weak environmental enforcement and low consumer demand for environment-friendly products mean there are few other drivers toward real improvement. Unfortunately, the available evidence seems to show that, at least initially, the conscripts far outnumber the "true believers" (Davy, 1996; Hamner, 1996). This may change over time, as firms go through the procedures and develop a greater organizational commitment to them and as customers and suppliers become used to dealing with environment-related issues as conditions of contract. But it should alert both businesses and governments to the limits of an ISO 14001-based strategy for environmental improvement.

\section{CERTIFICATION AND ACCREDITATION: A LACK OF CREDIBILITY?}

These problems are exacerbated by the current system of third-party certification. Under ISO 14001, an organization may choose to make a self-declaration of conformance without any outside review (ISO 14001, Introduction). A number of firms, especially within the United States, have stated that they will, for now at least, self-certify. Others seem to be adopting a strategy of obtaining third-party certification for their showcase plants, and then self-certifying their organizations as a whole. ${ }^{12}$ Because of the inherent credibility limits to self-declaration, both markets and regulators will probably be reluctant to accept such self-declarations, at least outside the SME context, and will require some outside verification of conformance with the standard.

ISO 14001 private or public sector certifiers may be accredited by any national accreditation body. No international standard regulates the composition or activities of ISO 14000 accreditation bodies, although several drafting exercises are in progress. ${ }^{13}$ At this point, therefore, the

12. This was the strategy announced by Bristol-Meyer-Squibb; it raises interesting questions about a company's ability to mislead suppliers and the public through such tactics (see "Certification or Self-Declaration," 1996).

13. The International Accreditation Forum, an association of accreditation bodies, has a working group on the subject. ISO has a Committee on Conformity Assessment (CASCO) that is also working on guidelines. CASCO Guide 61, General Requirements for Assessment and Accreditation of Certification/Registration Bodies, "sets out guidelines for a body 
accreditation of certifiers in one country does not guarantee that they will be acceptable in others. Indeed, one of businesses' objections to the ISO 9000 scheme has been that industry and governments in some states or groups of states have only accepted certifications from locally accredited individuals or firms, thus undermining the global nature of the standard and adding significantly to the costs of implementation. ${ }^{14}$ Some mutual recognition agreements exist ${ }^{15}$ but have not yet been extended to the environmental management arena.

Whereas lack of mutual recognition raises market access concerns, automatic recognition would raise credibility concerns because many accreditation bodies in APEC economies are closely tied to ministries of commerce and trade. In an effort to boost exports, they will be tempted to enforce less-than-rigorous procedures and oversight on certifiers. Therefore, mutual recognition of accreditation must go hand in hand with strict, mutually verified, and maintained guidelines.

Of more concern than the independence of accreditation bodies is both the independence and capacity of the third-party certifiers themselves. The credibility of ISO 14001, especially given the lack of public disclosure requirements, hinges on the credibility of the certification. If certifiers are seen as merely ratifying an empty exercise, the scheme will quickly lose value both in the market and in the eyes of regulators.

There are a number of reasons for concern that certification will be a less rigorous process than hoped for. First, many certifiers, especially in Asia, are closely connected to government export-promotion functions. For example, in Chinese Taipei, the Bureau of Commodity Inspection and Quarantine has issued about half the current ISO 9000 certifications at no cost to Taiwan companies and is expected to provide the same services for ISO 14000 at low or no cost (Mapes, 1996b). The bureau is under the Ministry of Economic Affairs. In Singapore, the Institute of Standards and Industrial Research, which carries out ISO 9000 certifications and is expected to do the same for ISO 14000 , is under the Ministry

to follow if it is to be recognized at a national or international level as competent and reliable, in assessing and subsequently accrediting certification bodies." Guide 62, General Requirements for Bodies Operating Assessment and Certification/Registration of Quality Systems, "specifies general requirements that a third-party operating quality system certification/registration shall meet, if it is to be recognized as competent and reliable in the operation of quality system certification/registration" ("Conformity Assessment," 1996). One problem in translating from the quality control to the environmental arena is that the concerns about disclosure and regulatory compliance that are central to the environmental management context do not apply to quality control.

14. See Thurston (1994). For example, one survey found that ISO 9000 certificates from the Philippines were rejected because of "lack of good reputation and a well known name" (quoted in United Nations Conference on Trade and Development [UNCTAD], 1996, p. 80, Box 5.2).

15. For example, Australia and New Zealand have a joint accreditation body (see Hulbert, 1996, p. 40); the U.S. and Canadian bodies are working toward mutual recognition ("Canadian Auditing," 1996). 
of Trade and Industry (Mapes, 1996a), as are two of the three accredited Indonesian ISO 9000 certifiers. In Malaysia, the government underwrites the cost of training seminars on ISO 14001 (D. Nelson, personal communication, September 30, 1996).

If the primary purpose of certification is to expand export opportunities, strong pressure will be brought to bear on certifiers to not fail any national industry applying for certification. Certifiers who develop a reputation for requiring tougher showings or who are less compliant than others are unlikely to be asked twice to certify companies. Under these circumstances, the end result may be a "race to the bottom" in which the least demanding certifiers garner the most business and those states that encourage less-than-thorough certification obtain the greatest number of certified companies with the accompanying export advantage. To these concerns, the ever-present problems of capture and corruption inherent in any oversight function must be added.

If large global purchasers and others demand only a paper certification, without any evidence of real performance improvement, the whole system may have limited environmental utility and devolve in merely an additional cost to business with only transient market value (Hamner, 1996). If, on the contrary, real improvement is required, there may be at least initial suspicion of national certifiers and a turn to well-known international firms. This will increase cost and worsen market access for developing countries but also provide a limit to the downward spiral described above. ${ }^{16}$

The probable dominance of certifiers from the quality control area who have expanded into ISO 14000 EMS certifications raises another set of problems. Quality control certifiers are trained to focus on systems and management functions; the predominance of ISO 9000-trained certifiers will reinforce the systems aspects of ISO 14001, with much less attention paid to the technical and performance-based aspects of performance improvement (Gunningham, 1996). Such certifiers may have little or no training in environmental science or in the chemical or biological sciences necessary to understanding the relevant questions, pollutiongenerating processes, or possible solutions.

\section{ISO in APEC: Playing to Strengths, Shoring up Weaknesses}

As noted above, many APEC economies are preparing to make use of the standards: Government agencies are gearing up to accredit certifiers and to aid in dissemination and in obtaining certification; and businesses

16. Studies show that domestic certifiers are far less expensive than their international (i.e., European or U.S.-based) counterparts (UNCTAD, 1996). 
are attending training sessions-some, mostly large multinational firms and large national firms in export sectors, have already sought certification. Within APEC itself, the environment ministers' meeting in July 1996 placed primary responsibility to develop the cleaner production strategy on the Industrial Science and Technology Working Group, together with the Human Resources Development Working Group, the Energy Working Group, and others, as appropriate (APEC, 1996, p. 3). The Human Resources Development Working Group is focusing on developing a Sustainable Development Training and Information Network that will provide training, information sharing, and technical capacity building on best practices in different industrial sectors (R. Schulberg, personal communication, August 22, 1996) ${ }^{17}$ The Industrial Science and Technology Working Group has to date focused on information and technology sharing; its agenda compared to ISO 14000 is under discussion.

It is not entirely clear where APEC's comparative advantage lies vis-à-vis other regional or international organizations in terms of supporting implementation of ISO 14001. It may be that for some aspects, organizations at the Association of Southeast Asian Nations (ASEAN) or Latin American level would make more sense. However, APEC's mixture of states/economies at different levels of development and with different regulatory cultures might prove useful. It could provide both technical and financial backing for capacity building in less developed countries and help shift the focus of environment professionals there toward pollution prevention. As important, the mixture of types of economies and legal cultures might lend greater credibility and opportunities for peer review to regional-level accreditation and oversight bodies. In addition, the existence of a number of big-market countries (Zarsky, 1996) might provide for a healthy competition among approaches. An APEC umbrella also ties the trade and market access issues directly into environmental improvement; it remains to be seen if the result will be watered-down environmental requirements in the name of trade liberalization or a synergy that will base increased access on real environmental progress.

If APEC uncritically embraces ISO 14001 per se, as seems to be the case to date, it will not necessarily lead to real environmental improvement. On the contrary, support for implementation of ISO 14001-related programs might siphon off resources that could be better used building effective domestic regulatory structures. Voluntary approaches such as ISO 14001 work best in the context of a clear, consistent, and welldeveloped regulatory structure that tells companies what laws and regulations they must comply with and that provides cost incentives for choosing clean production and clean technology. A focus on voluntary

17. Phone interview with Richard Schulberg, Oregon Economic Development Department. 
incentive programs cannot take away resources from capacity building, from coordination and implementation of strong regulatory frameworks within each APEC economy, or from efforts at convergence of such regulatory frameworks at a high level of protection. But APEC can play a positive role by focusing on three main areas that constitute the weaknesses of ISO 14001: performance, information generation and provision, and market access.

Such action should not focus on promotion of ISO 14001 as a standalone program but on a broader effort at building regional regulatory convergence and cooperation. This could include such areas as convergence in regulatory standards, joint testing protocols and laboratories, regional monitoring systems, and other initiatives that will help existing national and regional institutions work better.

\section{IMPROVING PERFORMANCE, NOT JUST SYSTEMS}

APEC can promote a role for more performance-based voluntary systems, including EMAS; various business-generated codes of conduct, such as the Coalition for Environmentally Responsible Economies Principles or BCSD; and national efforts along these lines. It can also spur training, information exchange, and the like for regulators from government environment ministries concerned with devising appropriate regulatory packages using EMSs.

With respect to EMAS, for firms that might wish to export to European markets, a joint ISO 14001/EMAS certification program would allow cost savings and also produce a more performance-oriented EMS. Such joint certification will find easier acceptance in Europe. Companies will probably be able to use ISO 14001 to comply with part, but not all, of the requirements for EMAS, ${ }^{18}$ but APEC-supported efforts should encourage companies to certify to both.

Another effort that might bear promotion through APEC structures involves the use of reputational incentives to encourage superior environmental performance being pioneered in Indonesia. The National Pollution Control Agency (BAPEDAL) in June 1995 launched the Program for Pollution Control, Evaluation and Rating (PROPER) (PROPERPROKASIH Team, 1995). Given weak enforcement ability and stretched regulatory resources in Indonesia, PROPER attempts to use public disclosure and reputational incentives to induce better industry performance in combination with a traditional regulatory system.

The program compiles water pollution data for 187 large industrial sources from existing regulatory programs combined with self-monitor-

18. Article 12 of EMAS (1993) allows national or international standards to be used for this purpose, but the standard must be approved for such use by the European Commission. The commission approved use of ISO 14001 to comply with most, but not all, EMAS provisions on April 22, 1997 ("Two Decisions," 1997). 
ing reports from polluters as well as inspections; it will expand toward coverage of air, water, and hazardous waste from all medium/large industrial sources. It then uses the data to rate each source based on five color performance categories. ${ }^{19}$ This avoids the traditional binary division into compliance and noncompliance, rewards continual improvement starting from whatever point a company is now at on this spectrum, and provides information to regulators from companies seeking a superior rating. Like ISO 14001, it relies on a judgment that companies (and the individuals who run them) care about their reputations for environmental responsibility and can be shamed into improving, but the focus is on performance, not systems. ${ }^{20}$ Indonesian regulators are currently exploring how ISO 14001 conformance could be used as part of their determination that a company deserves a green rating (BAPEDAL, n.d.).

Another spur for performance improvement would be to encourage involvement of local government and community representatives in environmental audits or reviews. For example, Japan uses business/ local government partnerships to work toward focused pollution reduction programs (Kawashima, 1995; Kurasaka, 1997). In the United States, several companies have entered into so-called good neighbor agreements, wherein they agree to local community participation in, and review of, environmental audits (Lewis, 1995).

Additionally, banks and insurance companies are a potentially potent source of environmental performance improvement. One expansion of a systems approach would be to combine it with specific performance indicators in requirements for project financing.

In contrast, promotion of a government mandate to industry to adopt the standard may not be wise and may even backfire. The tendency for most firms would be to go through the motions only, doing the minimum possible to comply with an external mandate. Moreover, requiring conformance would require additional enforcement resources, erasing one of the main potential advantages of an EMS from a regulator's viewpoint. Given the limits of ISO 14001 to compel performance improvement, the environmental advantage might be minimal, especially if expenditures on ISO 14001 replace or defer other more substantive efforts. In addition, if imports were subject to similar mandatory certification requirements, serious market access issues would arise. Nor should regulators grant exemptions, releases from legal requirements,

19. The five categories are black for total noncompliance, red for insufficient effort toward compliance, blue for bare-bones compliance, green for pollution levels at least $50 \%$ lower than discharge standards, and gold for having these minimum pollution levels plus similar levels of control for air and wastes, reaching high international standards through use of clean technology and the like.

20. Like ISO 14001, too, one of the weaknesses in this approach is the lack to date of public accessibility of the underlying data. To attempt to ensure their credibility with the public in the absence of disclosure, Indonesian regulators have adopted very stringent and conservative criteria for each rating category. 
or positive recognition to firms based solely on conformance with, or certification to, the standard. In short, EMS approaches are generally extraneous to regulatory systems and should be kept separate.

\section{EXPANDING INFORMATION COLLECTION AND ACCESS}

An increasing number of countries require reporting of information on environmental impacts and processes. The Malaysian Department of Environment, under the revised Environmental Quality Act, may mandate environmental auditing for seriously polluting facilities (see UNCTAD, 1996, p. 72). The Thai government requires major factories to regularly report and monitor emissions and effluents. The United States has proposed expanding the Toxics Release Inventory (TRI) to incorporate requirements to report on the quantity of chemicals generated as well as released, ${ }^{21}$ several U.S. state requirements go further, requiring reporting on inputs, consumption in-process and in-product as well as emissions and transfers. These mandatory reporting rules may facilitate introduction of ISO 14001 because companies will have to set up systems to obtain the necessary data anyway. APEC can encourage these efforts through training, information and technology sharing, and so forth.

Information provision is an important component of benchmarking efforts. In the benchmarking area, one problem is that the information now provided by companies, or gathered for their internal purposes, is usually not comparable: Definitions, reporting frequencies, and units of measure vary, and pollutant outputs are often not expressed in terms of amount of production. Several efforts are under way through ISO's subcommittee on environmental performance evaluation, the Organization for Economic Cooperation and Development [OECD], the United Nations, and North American regional trade bodies to develop more uniform registers that will permit cross-firm and cross-country comparisons (OECD, 1996). The World Bank is also engaged in potential benchmarking efforts through the construction of its Industrial Pollution Projection System (IPPS). ${ }^{22}$

21. Advance Notice of Proposed Rulemaking: Addition of Reporting Elements: Toxic Chemical Release Reporting; Community Right to Know, 61 Fed. Reg. 51322 (1996). The proposed regulations would expand the information required under the Toxics Release Inventory (TRI) to include materials accounting data.

22. The system focuses on defining pollution intensity and resource intensity upper and lower bounds for some 1,500 product categories, ranging from pesticides to food and drink. Although to date the underlying data are almost exclusively U.S. based, plans are under way to expand the database to include industries from a number of different countries. Once completed, the Industrial Pollution Projection System (IPPS) will provide one possible global measure of what emissions and resource use correlates with existing best practice on a product-by-product basis, giving companies achievable goals to move toward (Wheeler, Hettige, Martin, \& Signh, 1994). 
APEC could play a role developing and harmonizing regionwide environmental performance indicators that would allow cross-firm and cross-country comparisons and benchmarking. Performance indicators should measure progress toward cleaner production rather than simply measure compliance with local law. This work could be done in conjunction with work toward regionwide testing protocols, laboratories, and monitoring systems for pollutants, drawing in various sector-specific APEC working groups.

\section{HIGH-CREDIBILITY ACCREDITATION AND CERTIFICATION}

Creating an accreditation body that will have high standards and win global acceptability for its certifiers might be an appropriate activity for APEC to encourage. Some of the substantial costs of national bodies could be reduced through a regionwide accreditation body or, more modestly, development of a set of joint rules, peer review, and mutual recognition among a few subregional bodies (i.e., Pacific Accreditation Council, Latin American). ${ }^{23}$ A model exists in the European Accreditation of Certification, which recently agreed to mutual recognition of members' accreditations and the development of common guidelines (UNCTAD, 1996, p. 102). The APEC Committee on Trade and Investment's work program point on Standards and Conformance would be a natural liaison for this work.

Related work would help train more specialized certifiers with the required expertise in one or a few industrial sectors, who then certify industries in a wider geographical ambit than their own countries to help minimize worries about integrity. Japan has been developing this approach, encouraging sector-specific industry groups to prepare firms in their sector to adopt the standards. The Industrial Science and Technology Working Group could pull working groups on transportation, tourism, energy, and others into a regionwide effort. Rules might also allow for certifiers from different areas to cross-check each others' work as another way of increasing credibility.

In addition, market access could improve through regionwide initiatives to facilitate adoption of EMSs, although not necessarily ISO 14001 certification, by SMEs. This would involve training, financial assistance, and so forth and should be done in conjunction with the Committee on Trade and Investment's group on SMEs and with the Sustainable Development Training Network. Similarly, large global corporations should be encouraged to use their links with SME suppliers as well as purchas-

23. The International Accreditation Forum is working toward a multilateral agreement on recognizing each other's procedures and certificates, but it is unclear how long that process will take. A regional approach might prove easier (see "Japan: Environment," 1996). 
ers to provide training and technical assistance in implementing an EMS, perhaps through the concept of product stewardship.

Finally, APEC seems ideally suited to track and monitor the trade impacts of ISO 14001 on exporters from the region. ISO 14001 may well become a sine qua non for doing business in some sectors and some markets but not in others. To make better decisions, both governments and the private sector need up-to-date information on when certification is required; when other certifications, such as EMAS, BS 7750, or others are required; when specific environmental commitments are required as a condition of contract; and the like.

\section{Conclusion}

Reaching the overall goal of sustainable industrial development will require a combination of government regulation, industry self-regulation (such as ISO 14001), and public pressure. No one approach or seal of approval will automatically lead to improvement. An EMS is only the casing: The real issue is whether what is inside the casing is real or is just a paper effort. ISO 14001 should be considered, promoted, and discussed only as part of the larger question of routes to continual improvement of environmental performance.

Manuscript submitted January 5, 1997; revised manuscript accepted for publication April 30, 1997.

\section{Acknowledgments}

Many thanks to Lyuba Zarsky, Riva Krut, Harris Gleckman, David Nelson, and Ann Blake for their comments.

\section{References}

Asia Pacific Economic Corporation (APEC). (1996, July). APEC ministerial meeting on sustainable development, declaration and action programme (Document No. APEC 96/SDMIN, Rev. 1). Manila, Philippines: Author.

BAPEDAL. (n.d.). PROPER PROKASIH, Program for Pollution Control Evaluation and Rating [Mimeograph]. Jakarta, Indonesia: BAPEDAL.

Bell, C. (1997). The ISO 14001 environmental management systems standard: One American's view. In C. Sheldon (Ed.), ISO 14000 and beyond (pp. 61-92). Sheffield, UK: Greenleaf.

Bell, C., \& Connaughton, J. (1993, September 6). New global standards may guide industry on environmental issues. National Law Journal, p. 54.

California Environmental Protection Agency. (1996). Draft regulations to be added to Title 27, Div. 1, Chap. 4, Sec. 10400. Sacramento: Author. 
Canadian Auditing Association declares plans for auditor certification program. (1996, March). International Environmental Systems Update, p. 11.

Canadian court includes ISO 14001 certification in order. (1996, March). Business and the Environment, p. 2.

Canberra takes action on standards. (1996, July 15). Australian Financial Review, p. 1.

Cascio, J. (1994, April). International environmental management standards: ISO 9000's less tractable siblings. ASTM Standardization News, pp. 44, 47.

Certification or self-declaration: Weighing the options. (1996, May). Business and the Environment, p. 4.

China: East China port city designated "pilot city" for implementing ISO standard. (1997). International Environment Report Current Reports, 20(1), 21.

Chinese government considers ISO 14001 in regulations. (1996, July). International Environmental Systems Update, 3(7), 22.

Conformity assessment activities for EMS mirror ISO 9000 quality systems approach. (1996, March). International Environmental Systems Update, p. 15.

Davy, A. (1996). Environmental management systems: ISO 14001 issues for developing countries. In C. Sheldon (Ed.), ISO 14000 and beyond (pp. 169-183) Sheffield, UK: Greenleaf.

Establishing a European Eco-Management and Audit Scheme (EMAS), Council Regulation 1836/93, O.J. (L 168) (1993).

General Agreement on Tariffs and Trade (GATT). (1994). Final act embodying the results of the Uruguay Round of multilateral trade negotiations. Geneva, Switzerland: Author.

Gunningham, N. (1995). Environment, self-regulation, and the chemical industry: Assessing responsible care. Law \& Policy, 17.

Gunningham, N. (1996, July). From adversarialism to partnership? ISO 14000 and regulation. In ISO 14000: Regulation, trade and environment. Canberra: Australian Centre for Environmental Law.

Hamner, B. (1996). A strategic approach to ISO 14000. Corporate Environmental Strategy, 4(2), 46.

Hulbert, J. L. (1996, July). Environmental management systems: International trade and regional issues. In ISO 14000: Regulation, trade and environment (pp. 4-5). Canberra: Australian Centre for Environmental Law.

Indonesia adopts ISO 14001 as national standard. (1996, December). Business and the Environment's ISO 14000 Update, p. 3.

International Institute for Sustainable Development (IISD). (1997). Global green standards: ISO 14000 and sustainable development. Winnipeg, Canada: Author.

Japan agrees to embrace ISO system of environmental supervision programs. (1994, October 19). International Environmental Reporter-Current Reports, p. 862.

Japan: Environment agency program to encourage small entities, public sector to use ISO 14000. (1996, October 16). International Environmental Reporter-Current Reports, p. 291.

Johnson, P. L. (1993). ISO 9000: Meeting the new international standards. New York: McGrawHill.

Kawashima, S. (1995). A survey of environmental law and policy in Japan. North Carolina Journal of International Law and Commercial Regulation, 20, 231.

Kurasaka, T. (1996). Attitudes and experiences of the Japanese business community vis-àvis EMS standards. In C. Sheldon (Ed.), ISO 14000 and beyond (pp. 155-168). Sheffield, UK: Greenleaf.

Lewis, S. (1995). Precedents for corporate community compacts and good neighbor agreements. Waverly, MA: Good Neighbor Project.

Mapes, J. J. (1996a, August). ISO 14000 in Asia: Taiwan case study. Paper presented at the Conference on Actually Implementing ISO 14000, San Francisco.

Mapes, J. J. (1996b, January). Status of ISO 14000 in the countries of the Association of South East Asian Nations. Washington, DC: ASEAN Environmental Improvement Project. 
Organization for Economic Cooperation and Development (OECD). (1996). Pollutant release and transfer registers (PRTRs): A tool for environmental policy and sustainable development, guidance manual for governments. Paris: Author.

PROPER-PROKASIH Team, BAPEDAL and PRDEI, World Bank. (1995). What is PROPER? Reputational incentives for pollution control in Indonesia. Unpublished manuscript.

Robinson, B. (1996). ISO 14000: Eagle or albatross? In ISO 14000: Regulation, trade and environment. Canberra: Australian Centre for Environmental Law.

Roht-Arriaza, N. (1995). Shifting the point of regulation: The international organization for standardization and global lawmaking on trade and the environment. Ecology Law Quarterly, 22, 479.

Singapore launching program to help SMEs understand requirements of ISO 14000 series. (1996, November 13). International Environmental Reporter - Current Reports, p. 23.

Thurston, C. W. (1994). Quality is a global affair: Worldwide adoption of International Organization for Standardization Program, Quality '94. Chem. Marketing Reports, 246, SR-10.

Two decisions officially recognize ISO 14001 as covering majority of EMAS rule. (1997, May 14). International Environmental Reporter-Current Reports, p. 467.

United Nations Conference on Trade and Development (UNCTAD). (1996). ISO 14001: International environmental management systems standards: Five key questions for developing country officials. [Draft for comment.] Geneva, Switzerland: Author.

United Nations Industrial Development Organization (UNIDO). (1996, February). Trade implications of international standards for quality and environmental management systems: Survey results. Geneva, Switzerland: Author.

United States-Asia Environmental Partnership (U.S.-AEP). (1996a). Country assessment: Indonesia. Washington, DC: Author.

United States-Asia Environmental Partnership (U.S.-AEP). (1997b). Country assessment: Malaysia. Washington, DC: Author.

United States-Asia Environmental Partnership (U.S.AEP). (1996c). Country assessment: Singapore. Washington, DC: Author.

United States-Asia Environmental Partnership (U.S.-AEP). (1996d). Country assessment: Taiwan. Washington, DC: Author.

United States-Asia Environmental Partnership (U.S.-AEP). (1996e). Country assessment: Thailand. Washington, DC: Author.

U.S. Environmental Protection Agency (EPA). (1992, May). Facility pollution prevention guide (Document No. EPA/600/R-92/088). Washington, DC: Author.

U.S. Environmental Protection Agency (EPA) (1996). ELP proposed framewark (Document No. EPA 305-F-96-012). Washington, DC: Author.

Wheeler, D., Hettige, H., Martin, P., \& Singh, M. (1994). The industrial pollution projection system [On-line]. Available: http:///www.worldbank.org/html/prdei/ipps/ipphome. html

Zarsky, L. (1996). APEC and the environment: Guiding principles, innovative strategies. Berkeley, CA: Nautilus Institute.

Naomi Roht-Arriaza is a professor of law at the University of California, Hastings College of Law. 